\title{
Comparative structural and functional studies of avian and mammalian hemoglobins ${ }^{\star}$
}

\author{
Davood Ajloo ${ }^{1,2}$, Ali A. Moosavi-Movahedi ${ }^{1 凶}$, Mahdi Sadeghi $^{1}$ and Housain Gharibi ${ }^{2}$ \\ ${ }^{1}$ Institute of Biochemistry and Biophysics, University of Tehran, Tehran, Iran; ${ }^{2}$ Department of \\ Chemistry, Faculty of Science, Tarbiat Modarres University, Tehran, Iran
}

Received: 17 September, 2001; revised: 22 January, 2002; accepted: 13 February, 2002

Key words: avian hemoglobin, mammalian hemoglobin, hydrophobicity, computational methods, thermodynamic stability

\begin{abstract}
Thermal stabilities of chicken, grey lag goose (Anser anser), turkey as avian hemoglobins (Hbs); and human, bovine, sheep and horse as mammalian Hbs in hemolysate form were investigated and compared with oxygen affinities taken from literature. The thermal stability was obtained from thermal profiles using temperature scanning spectrophotometry. The buffer conditions were $50 \mathrm{mM}$ Tris, $\mathrm{pH} \mathrm{7.2,}$ and $1 \mathrm{mM}$ EDTA. The average of the inverse temperature transitions, average hydrophobicity, total van der Waals volume, partial molal volume and hydration potential were calculated by computational methods. The hemolysed avian Hbs have a lower oxygen affinity, higher thermal stability and higher self association than the mammalian Hbs. These observations are based on amino-acid composition, influence of ionic effectors, and the presence of $\mathrm{Hb} \mathrm{D}$ in several avian Hbs. The results indicate that the avian Hbs have a more tense (T) conformation than the mammalian Hbs.
\end{abstract}

The respiratory system of birds differs from that of mammals; whereas their hemoglobins are functionally similar. Oxygen affinities of mammalian and avian hemoglobins have been studied by a number of investigators who have found the presence of inositol pentaphosphate $\left(\mathrm{IP}_{5}\right)$ in the birds blood in- stead of 2,3-diphosphoglycerate, DPG, found in mammalian blood (Lenfant et al., 1969; Christensen \& Dill, 1965; Bartels et al., 1966; Tuker, 1972; Knapp et al., 1999). The agent that is generally used to study the hemoglobin-phosphate interactions in vitro is inositol hexaphosphate (IHP) (Rollema \&

\footnotetext{
The financial support provided by Research Council of University of Tehran is gratefully acknowledged.

${ }^{\circledR}$ To whom correspondence should be addressed: tel: (98 21) 640 3957; fax: (98 21) 640 4680; e-mail : Moosavi@ibb.ut.ac.ir

Abbreviations: DPG, 2,3-diphosphoglycerate; DTAB, dodecyltrimethylammonium bromide; IHP (IP 6 ), inositol hexaphosphate; $\mathrm{IP}_{5}$, inositol pentaphosphate; $p_{50}$, pressure at half saturation of hemoglobin; $T(\mathrm{~g})$, temperature at midpoint of thermal changes of turbidity, measured as variation in absorbance at $700 \mathrm{~nm} ; T_{\mathrm{m}}$, temperature at midpoint of thermal denaturation; $T_{\mathrm{t}}$, inverse temperature transition.
} 
Bauer, 1979; Brygier et al., 1975; Coletta et al., 1993; Messana et al., 1998).

Cho \& Choy (1980) studied the thermal stabilities of various methemoglobin and metmyoglobin derivatives in the presence of different ligands and at different $\mathrm{pH}$ values by differential scanning calorimetry (DSC). As a result, they concluded that the thermal denaturation of $\mathrm{Hb}$ derivatives could be described by an activated two-state process and determined corresponding parameters of activation. The stability of normal and cross-linked hemoglobins was studied on the assumption of a two-state model for denaturation of $\mathrm{Hb}$ derivatives (Yang \& Olsen, 1988). The relationship between thermal stability and hydrophobicity has been studied very extensively (Jiang et al., 2001; Irback \& Sanderlin, 2000; Wagschal et al., 1999; Kumar et al., 2000). A number of researchers believe that this relationship should be the method of choice for studying the hemoglobins of birds and mammals (Irback \& Sanderlin, 2000; Petruzzelli et al., 1996; Bull \& Breese, 1973). For example, Bull \& Breese (1973) have suggested a relationship between stability and hydrophobicity of hemoglobins from animal sources. It has been suggested that the stability of proteins at high temperature $\left(60-70^{\circ} \mathrm{C}\right)$ is due to enhanced hydrophobic bonding interactions (Bull \& Breese, 1973). Also Bigelow \& Channon (1976) believed that the hydrophobic character of proteins could be the determining factor of their stability and proposed a method for the calculation of average degree of hydrophobicity of thermophilic proteins. Once the method was applied, they found the hydrophobicity of the thermophilic proteins was by $10 \%$ higher than that of normal proteins. It should be noted that the correlations between quaternary structures and stabilities and functions of proteins were also studied by the accessible and the buried surface area calculations (Chothia et al., 1976). Hydrophobic interactions affect also polymerization of biomolecules (Urry et al., 1992; Adachi et al., 1987; Adachi et al., 1993; Yohe et al., 2000).
The role of these interactions in increasing the association or polymerization of $\mathrm{Hb} \mathrm{S}$ (Harrington et al., 1997) and lamprey $\mathrm{Hb}$ (Andersen \& Gibson, 1971) has been already investigated. Increments in phosphate concentration and temperature were found to increase the rate of polymerization (Yohe et al., 2000).

Total free energy of unfolding is obtained by calculating the sum of two energy contributions, i.e conformational and hydration energy. Hydration affects the empirical conformational energy values. The free energy of hydration is composed of additive contributions of various functional groups of proteins. The hydration of each group is assumed to be proportional to the accessible surface area of the group (Ooi et al., 1987). The energy of unfolding is considered as a measure of protein stability (Jiang et al., 2001; Ooi et al., 1987; Koehl \& Levitt, 1999).

Koehl \& Levitt (1999) have developed a protein design procedure that optimizes whole sequences for a given target conformation based on the knowledge of template backbone and on semiempirical potential energy function. This energy function is purely physical including steric interaction based on Lennard-Jones potential, electrostatic interaction based on a Coulomb potential, and hydrophobicity in the form of an environment free energy based on accessible surface area and interatomic contacts. The constants of proportionality, representing the free energy of hydration per unit area of accessible surface, have been evaluated for seven classes of groups (Koehl \& Levitt, 1999).

In this study we have compared the stabilities and functions of several mammalian and avian hemoglobin samples by using various experimental and computational methods.

\section{MATERIALS AND METHODS}

DEAE-Sephadex A-50, and Sephadex G-25 filtration gels were obtained from Pharmacia 
Fine Chemicals. Dodecyltrimethylammonium bromide (DTAB), Tris, and inositol hexaphosphate (IHP) were obtained from Sigma.

Hemoglobin samples from fresh blood of humans, bovine, sheep, horse and greylag goose were obtained from the Blood Transfusion Organization, Slaughter House, and The School of Veterinary Medicine, University of Tehran, respectively.

\section{Preparation of $\mathbf{H b}$}

The heparinized blood samples were washed three times with $0.9 \% \mathrm{NaCl}$. After each wash, the sample was centrifuged at 3000 r.p.m. Afterwards, the packed cells were lysed with 5 portions of double distilled water, and the sample was centrifuged at 10000 r.p.m. Subsequently, $5 \%(\mathrm{w} / \mathrm{v}) \mathrm{NaCl}$ was added to the sample and the mixture was centrifuged at 18000 r.p.m. All the steps were carried out at $4^{\circ} \mathrm{C}$, and each centrifugation step was carried out for a period of $15 \mathrm{~min}$. The method of Williams \& Tsay (1973) was applied. All samples were dialyzed against a buffer: $50 \mathrm{mM}$ Tris, $\mathrm{pH} 7.2$, and $1 \mathrm{mM}$ EDTA.

The dialyzed samples from chicken were purified by chromatography in $4.5 \times 10 \mathrm{~cm}$ DEAE Sephadex A-50 (Cobb et al., 1992). The major component of $\mathrm{Hb} \mathrm{A}$ was eluted immediately and then $\mathrm{Hb} \mathrm{D}$ was eluted with the same buffer solution containing $0.03 \mathrm{M} \mathrm{NaCl}$. After separation of $\mathrm{Hb} \mathrm{A}$ and $\mathrm{Hb} \mathrm{D}$, each was concentrated by ultrafiltration through the Amicon filter. The chicken hemoglobin was separated from the organic phosphate by gel filtration on Sephadex G-25 in $0.1 \mathrm{M}$ Tris/HCl, pH 8.5 and $0.5 \mathrm{M} \mathrm{NaCl}$ (Rollema \& Bauer, 1979).

\section{Spectrophotometry}

The Gilford spectrophotometer (model 2400-2) was used for obtaining the thermal profiles of hemoglobin solutions, using wave- lengths of 280 and $700 \mathrm{~nm}$ for the conformational and the turbidity studies, respectively. The scan was run at a rate of $1 \mathrm{~K} / \mathrm{min}$ in a degassed buffer solution.

\section{Theoretical calculations}

The single point energy was determined by the AMBER force field (scale factor 4) implemented in Hyperchem 5.02 version. Data for the human (PDB file is 1hho.pdb) and the bar-headed goose (PDB file is 1a4f.pdb) $\mathrm{Hbs}$ were used (Zhang et al., 1996). The conformational energies $(E)$ in folded and unfolded or extended forms $\left((\phi, \psi, \omega)=\left(-155^{\circ}\right.\right.$, $\left.160^{\circ}, 180^{\circ}\right)$ ) were obtained for the dimers and monomers. The hydration free energy, $\Delta G_{\mathrm{h}}$, was calculated by using the group hydration $\left(g_{i}\right)$ values (Table 3) taken directly from (Ooi et al., 1987) for the corresponding $\mathrm{Hb}$ conformation. The difference between the dimers (in folded conformation) and the monomers (in unfolded conformation) as well as the differences between the hydration energy, $\Delta G_{\mathrm{h}} \mathrm{t}$, and the conformational energy, $\Delta E^{\mathrm{t}}$, were calculated as follows:

$$
\begin{aligned}
\Delta G_{\mathrm{h}} & =\sum_{i} g_{i}(\mathrm{ASA})_{i} \\
\Delta G_{\mathrm{h}}^{\mathrm{t}} & =\sum_{j=\alpha, \beta} \Delta G_{\mathrm{h}}(u)_{j}-\Delta G_{\mathrm{h}}(f)_{\alpha, \beta} \\
\Delta E^{\mathrm{t}} & =\sum_{j=\alpha, \beta} E(u)_{j}-E(f)_{\alpha, \beta}
\end{aligned}
$$

Where, $f, u, \alpha, \beta, \alpha \beta$ represent the folded and unfolded conformation, monomers and dimer subunits, respectively. The accessible surface area (ASA) was computed based on the methods of Shrake \& Rupley (1973). This method was implemented in the Fantom (http://www. scsb.utmb.edu) and Naderi-manesh and coworkers (Naderi-manesh et al., 2001) programs. The total energy of unfolding was obtained as follows:

$$
\Delta G_{u}=\Delta G_{\mathrm{h}}^{\mathrm{t}}+\Delta E^{\mathrm{t}}
$$


The buried surface area, $\triangle \mathrm{ASA}$, for the oligomers is defined as the sum of the accessible area of the monomers minus that of the dimer, and correlates with the stability. The gap volume is a void space in the interface between the subunits. It was calculated for the same PDB files of human oxy $\mathrm{Hb}$ and the bar-headed goose $\mathrm{Hb}$ using the web site (www.biochem.ucl.ac.uk).

All of the physical parameters for proteins such as average hydrophobicity, $\mathrm{H} \phi$, average inverse transition temperature, $\left\langle T_{\mathrm{t}}\right\rangle$, total van der Waals volume, $\mathrm{V}_{\mathrm{t}}$, total hydration potential, $\mathrm{HP}^{\mathrm{t}}$, and average partial molal volume, $\langle v\rangle$, were calculated by using amino acid parameters, i.e. hydrophobicity index, HI (Argos et al., 1982) inverse of transition temperature, $T_{\mathrm{t}}$, (Urry et al., 1992), $\left(T_{\mathrm{t}} \equiv T_{(\mathrm{g})}\right.$ is the temperature at which the turbidity measured at $700 \mathrm{~nm}$ reaches the half-maximal value), van der Waals volume, $\mathrm{V}_{\mathrm{v}}$ (Chalikian et al., 1996), hydration potential, HP (Argos et $a l .$, 1982), and partial specific volume, $v$ (Prakash, \& Timasheff, 1985), respectively. The cited average parameters were calculated as the sum of the parameters for amino acids (Table 2) divided by the number of amino acids.

\section{RESULTS}

Figure 1 shows the denaturation profiles at $280 \mathrm{~nm}$ for the oxyhemoglobin samples. It points to the higher melting temperature, $T_{\mathrm{m}}$, considered as a stability criterion, for the avian as related to the mammalian $\mathrm{Hb}$ samples. Figure 2 shows the direct relationship between $T_{\mathrm{m}}$ of hemoglobins in buffer condition and $p_{50}$ of mammalian and avian blood, taken directly from literature and collected in Table 1. The data indicate that lower oxygen affinity is consistent with the higher stability of hemoglobins. The hydrophobicity, $\mathrm{H} \phi$, of 33 hemoglobins ( $\mathrm{Hb} \mathrm{A}$ ), downloaded from (Swiss-Prot) data base, was calculated as the sum of the amino acids hydrophobicity index, HI, which is tabulated in Table 2. Figure 3 shows the average hydrophobicity, $\mathrm{H} \phi$, and the average inverse transition temperature, $\left\langle T_{\mathrm{t}}\right\rangle$, for the avian and the mammalian hemoglobins. This Figure also points to a higher hydrophobicity and a lower $\left\langle T_{\mathrm{t}}\right\rangle$ for the association criterion of the avian as compared with the mammalian Hbs. The variation of absorbance at $700 \mathrm{~nm}$ as a turbidity parameter versus temperature and (DTAB) (Fig. 4) points to a higher turbidity of the avian as

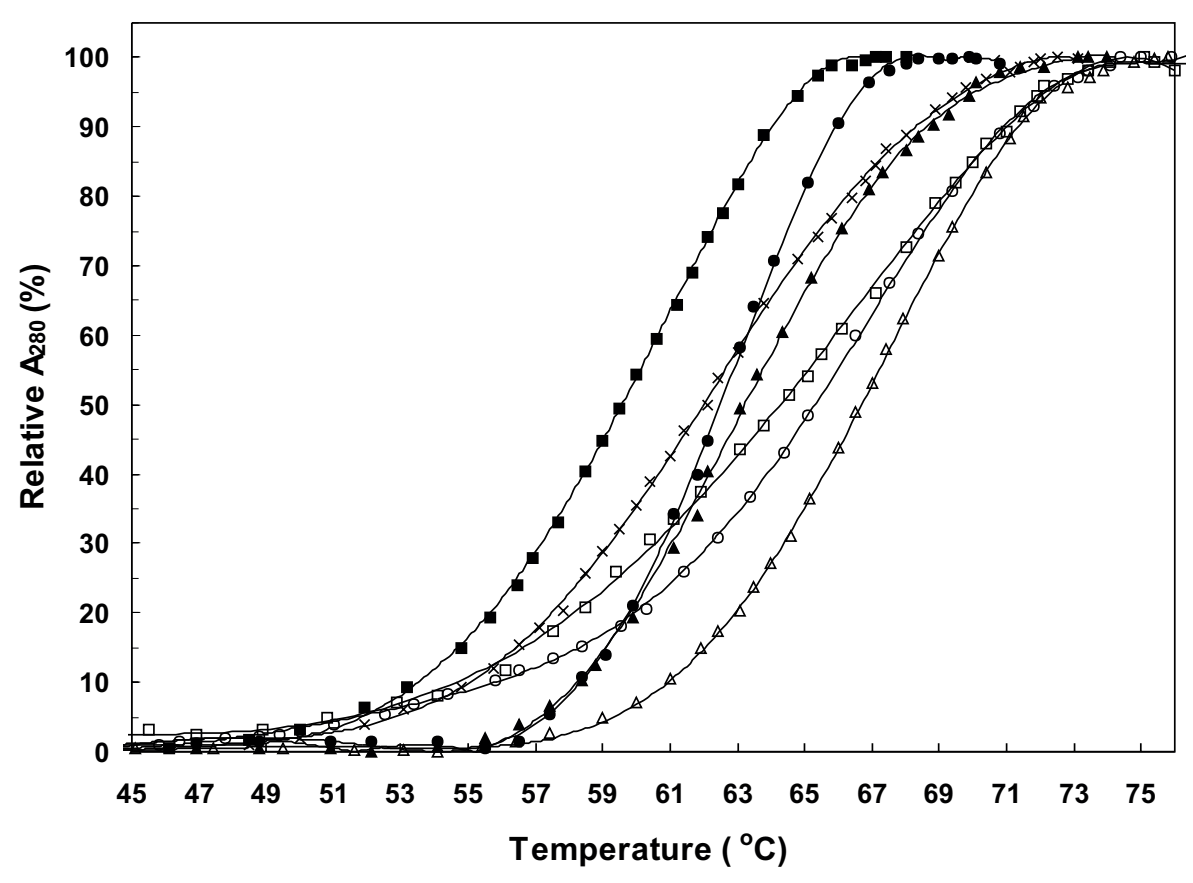

Figure 1. Thermal stability profiles of oxyhemoglobin in $\mathbf{5 0} \mathbf{~ m M ~ T r i s ~}$ buffer, pH 7.2, and $1 \mathrm{mM}$ EDTA at $280 \mathrm{~nm}$, for chicken ( $\square$ ), turkey ( $($ ), goose $(\Delta)$, human ( $\Delta)$, bovine (O), horse ( $\square$ ), sheep $(x)$ hemoglobins. 


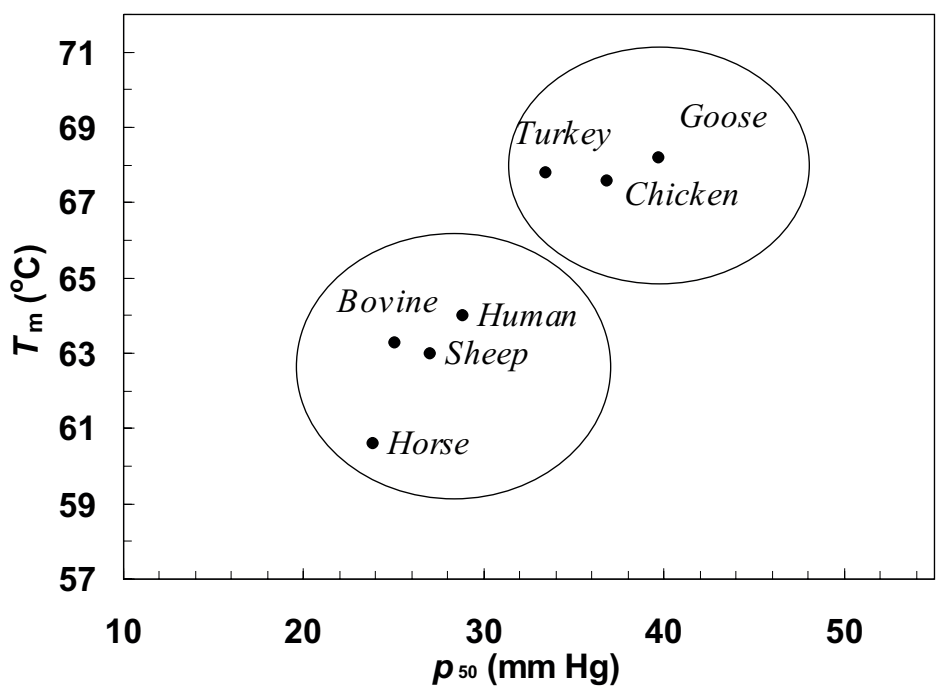

Figure 2. The relationship between midpoint of thermal transition, $T_{\mathrm{m}}$ (our experiment) at $280 \mathrm{~nm}$ and blood oxygen affinity $\left(p_{50}\right)$ taken directly from literature (Lenfant et al., 1969; Christensen \& Dill, 1965; Bartels et al., 1966; Tuker, 1972; Knapp et al., 1999; Adachi et al., 1987; Yohe et al., 2000; Harrington et al., 1997; Andersen \& Gibson, 1971).

compared to the mammalian Hbs. The experimental and calculated parameters for avian and mammalian hemoglobins are listed in Table 1.

The conformational energy, $\Delta E^{\mathrm{t}}$, for the bar-headed goose and human Hbs were ob- static and the van der Waals energies of the samples are tabulated in Table 4 .

The results show that the stability parameter, $\Delta G_{u}$, has a higher value for birds (e.g. goose) than for mammals (e.g. humans). In general, a higher conformational stability for

Table 1. Experimental and calculated parameters for avian and mammalian hemoglobins

\begin{tabular}{llllllll}
\hline & Goose & Chicken & Turkey & Human & Sheep & Bovine & Horse \\
\hline$p_{50}{ }^{\mathrm{a}}$ & 39.7 & 36.8 & 33.4 & 28.8 & 27 & 25 & 23.8 \\
$T_{\mathrm{m}}{ }^{\mathrm{b}}$ & 68.2 & 67.6 & 67.8 & 64 & 63 & 63.3 & 60.6 \\
$T(\mathrm{~g})^{\mathrm{c}}$ & 62.2 & 58.8 & 59.4 & 66.4 & 66.4 & 65.4 & 64.4 \\
$\left\langle T_{\mathrm{t}}\right\rangle^{\mathrm{d}}$ & 47.8 & 47.5 & 47.0 & 47.9 & 49.7 & 50.2 & 49.8 \\
$\mathrm{H} \phi^{\mathrm{e}}$ & 538 & 544 & 547 & 516 & 502 & 49077 & 505 \\
$\langle v\rangle^{\mathrm{f}}$ & 0.745 & 0.746 & 0.746 & 0.743 & 0.738 & 0.738 & 0.741 \\
$V_{t}^{\mathrm{g}}$ & 59736 & 59838 & 59836 & 58372 & 58664 & 58280 & 58644 \\
$\mathrm{HP}^{\mathrm{t}, \mathrm{h}}$ & 341.1 & 341.5 & 341.4 & 339.5 & 334.0 & 340.0 & 338.0 \\
\hline
\end{tabular}

${ }^{\mathrm{a}} p_{50}$, pressure at half saturation of hemoglobin directly taken from literature (Lenfant et al., 1969; Christensen \& Dill, 1965; Bartels et al., 1966; Tuker, 1972; Knapp et al., 1999; Gustin et al., 1988; Clerboux et al., 1993; Bard et al., 1976); ${ }^{\mathrm{b}} T_{\mathrm{m}}$ obtained from Fig. $1 ;{ }^{\mathrm{c}} T_{t}$ (g), midpoint of absorbance at $700 \mathrm{~nm}$ vs temperature plot (turbidity) for oxyhemoglobin; ${ }^{\mathrm{d}}\left\langle T_{\mathrm{t}}\right\rangle$, calculated average inverse of transition temperature; ${ }^{\mathrm{e}} \mathrm{H} \phi$, calculated average hydrophobicity; ${ }^{\mathrm{f}}\langle v\rangle$, calculated average partial molal volume; ${ }^{\mathrm{g}} \mathrm{V}_{\mathrm{t}}$, total van der Waals volume; ${ }^{\mathrm{h}} \mathrm{HP}^{\mathrm{t}}$, calculated hydration potential.

tained by theoretical calculations. The free energy of unfolding, $\Delta G_{u}$, is the sum of the hydration and conformational energies (Ooi et al., 1987). The difference between the dimer and the monomer hydration energies were obtained from the group hydration data taken from Ooi et al. (1987) (see Table 3). The conformational, $\Delta E^{\mathrm{t}}$, unfolding, $\Delta G_{u}$, electro- dimer goose $\mathrm{Hbs}$, from our experiment, could be deemed as a characteristic feature for the avian compared with the mammalian Hbs.

The buried surface area, $\triangle \mathrm{ASA}$, gap volume, $\mathrm{V}_{\mathrm{G}}$, melting temperature, $T_{\mathrm{m}}$, for some representative oxyhemoglobins are listed in Table 5 . These data will be discussed further in the text. 
Table 2. Parameters for amino acids used in this work

\begin{tabular}{|c|c|c|c|c|c|}
\hline $\begin{array}{l}\text { Amino } \\
\text { acid }\end{array}$ & $\mathrm{HI}$ & $T_{\mathrm{t}}$ & $\mathrm{V}_{\mathrm{v}}$ & $\mathrm{HP}$ & $v$ \\
\hline Ala & 0.61 & 45 & 67 & 2.00 & 0.74 \\
\hline Arg & 0.60 & 60 & 148 & 0.00 & 0.70 \\
\hline Asn & 0.06 & 50 & 96 & 0.20 & $0.63^{\mathrm{a}}$ \\
\hline Asp & 0.46 & 150 & 91 & 0.01 & 0.60 \\
\hline Cys & 1.07 & 30 & 86 & 1.51 & 0.61 \\
\hline Gln & 0.00 & 60 & 114 & 0.25 & $0.66^{\mathrm{a}}$ \\
\hline Glu & 0.47 & 250 & 109 & 0.13 & 0.66 \\
\hline Gly & 0.07 & 55 & 48 & 2.07 & 0.64 \\
\hline His & 0.61 & 30 & 118 & 0.12 & 0.67 \\
\hline Ile & 2.22 & 10 & 124 & 0.23 & 0.90 \\
\hline Leu & 1.53 & 5 & 124 & 2.06 & 0.90 \\
\hline Lys & 1.15 & 35 & 135 & 0.23 & 0.82 \\
\hline Met & 1.18 & 20 & 124 & 1.47 & 0.75 \\
\hline Phe & 2.02 & -30 & 135 & 1.58 & 0.77 \\
\hline Pro & 1.95 & -8 & 90 & 0.93 & 0.76 \\
\hline Ser & 0.05 & 50 & 73 & 0.92 & 0.63 \\
\hline Thr & 0.05 & 50 & 93 & 0.94 & 0.70 \\
\hline $\operatorname{Trp}$ & 2.65 & -90 & 163 & 0.79 & 0.74 \\
\hline Tyr & 1.88 & -55 & 141 & 0.75 & 0.71 \\
\hline Val & 1.32 & 24 & 105 & 2.00 & 0.86 \\
\hline
\end{tabular}

HI, Hydrophobicity index (Argos et al., 1982); $T_{\mathrm{t}}$, inverse of temperature transition (Urry et al., 1992); $V_{v}$, van der Waals volume (Chalikian et al., 1996); HP, hydration potential; $v$ (ml/g), partial molal volume (Prakash \& Timasheff, 1985);

${ }^{a}$ Values estimated from a direct correlation between van der Waals volume and partial molal volume.

Table 3. The computed $g$ coefficient for free energy of hydration ${ }^{\text {a }}$

\begin{tabular}{lc}
\hline Class of chemical group & $g\left(\mathrm{kcal} / \mathrm{mol} \cdot \AA^{2}\right)$ \\
\hline Aliphatic carbon & 0.008 \\
Aromatic carbon & -0.008 \\
Hydroxyl & -0.172 \\
Amide and amine & -0.132 \\
Carboxyl and carbonyl carbon & 0.427 \\
Carboxyl and carbonyl oxygen & -0.038 \\
Sulfur and thiol & -0.021 \\
\hline
\end{tabular}

${ }^{\mathrm{a}}$ Data are taken from (Ooi et al., 1987).

\section{DISCUSSION}

Our results indicate a reversed relationship between the oxygen affinity and the melting temperature, $T_{\mathrm{m}}$, i.e., an increase in the stability is directly related to a decrease in the oxygen affinity (Fig. 2). In our experiments, we have used seven hemoglobin samples (avian and mammalian) in hemolysate form. Our data show that higher temperature Hbs stability in birds is related to lower oxygen affinity. The higher stability of avian as compared to mammalian $\mathrm{Hb}$ is believed to be due to the differences in their amino-acid composition (Kumar et al., 2000), the presence of ionic effectors (Rollema \& Bauer, 1979; Brygier et $a l ., 1975)$ and/or the influence of $\mathrm{Hb} \mathrm{D}$ (Knapp et al., 1999).

Avian Hbs contains more hydrophobic amino-acid residues than mammalian $\mathrm{Hbs}$ (Fig. 3). This observation is consistent with the presence of a higher content of hydrophobic residues in avian hemoglobin, its higher thermal stability and attainment of a tense (T) state. The conservation of hydrophobic domains in proteins such as the avian Hbs might have, in fact, required the stabilization of tertiary structure, in order to maintain the function of the protein through a long period of evolution (Perutz, 1983).

It has been reported that an extra positive charge in the cavity site of avian $\mathrm{Hb}$ (Moss \& Hamilton, 1974) led to a stronger binding of ionic effectors in birds than it has been observed in mammals (Brygier et al., 1975). It led also to a higher $\mathrm{R} \rightarrow \mathrm{T}$ transition for the avian $\mathrm{Hb}$. In fact, the ionic effectors, which for mammals and birds are DPG and $\mathrm{IP}_{5}$, respectively, exhibit a stronger binding in deoxy forms leading to decreased Hbs oxygen affinity. The number of negative charges in $\mathrm{IP}_{5}$ seemed to be higher than in DPG. As a result, the binding constant for $\mathrm{IP}_{5}$ with $\mathrm{Hb}$ is higher than that for DPG (Rollema \& Bauer, 1979; Brygier et al., 1975). It has been noted that the ionic effectors increase the Hill coefficient (Knapp et al., 1999), tetramer association 


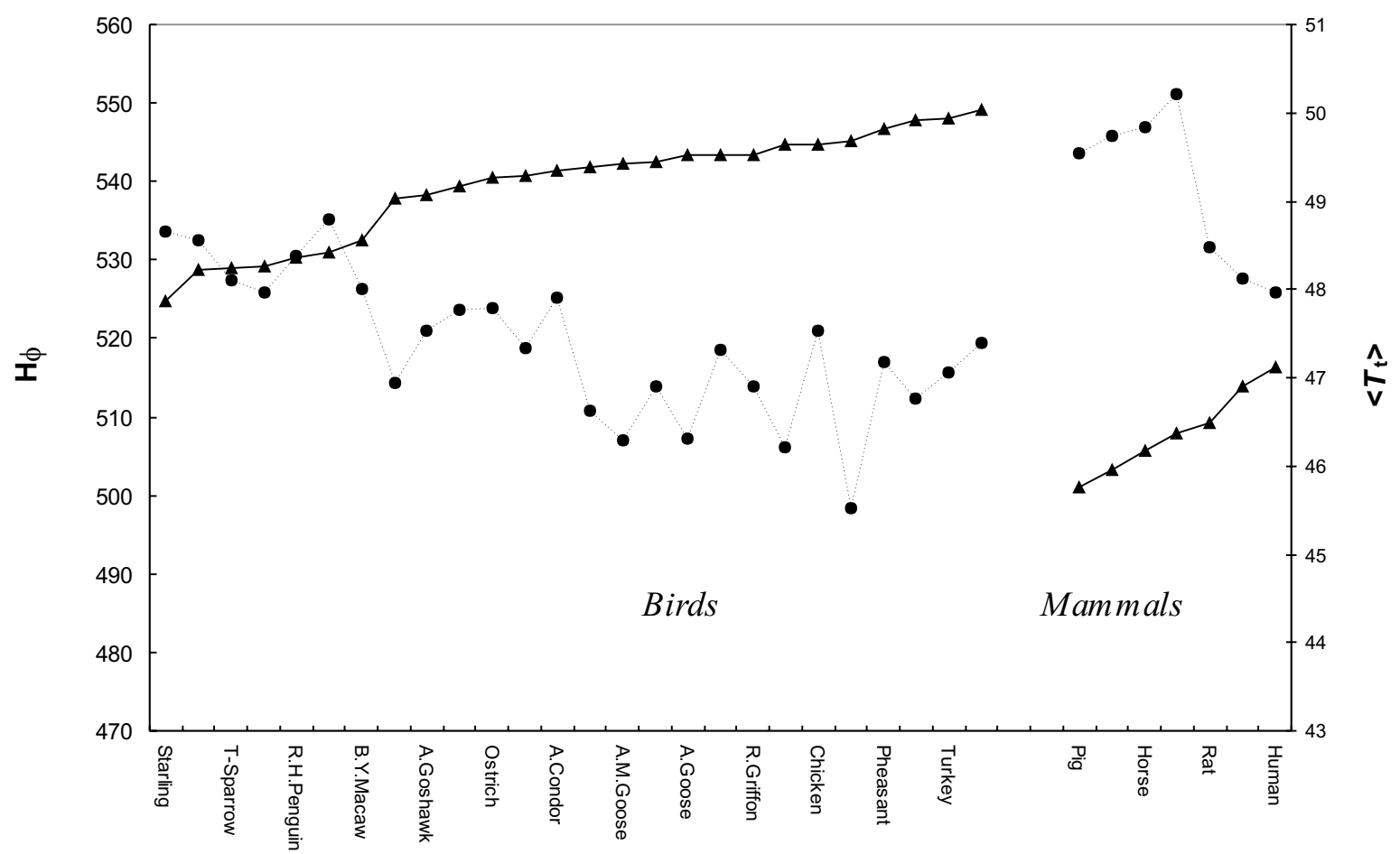

Figure $3 . \mathrm{H} \phi(\Delta)$ and $\left\langle T_{t}\right\rangle(\bullet)$ values for 33 hemoglobins (from birds and mammals) calculated from amino-acid parameters, as described under Methods.

(Yohe et al., 2000) and stability of $\mathrm{Hb}$ (cf. data for IHP in Table 5).

Knapp and coworkers (Knapp et al., 1999) have reported that the presence of $\mathrm{Hb} \mathrm{D}$ component in $\mathrm{Hb}$ from several birds induces a lower oxygen affinity and that formation of a large tetramer-tetramer interface in chicken $\mathrm{Hb} \mathrm{D}$ mediates a shift in the helix of $\alpha \beta$ subunits in such a way that the distal histidine is pushed further into the heme pocket, as it was also observed in lamprey deoxy $\mathrm{Hb}$. Since the resulting position of the distal histidine hinders the oxygen binding, the oxygen affinity is reduced. Avian Hbs have a lower oxygen affinity than the mammalian Hbs. One reason for the reduction of oxygen affinity in the birds is the presence of $\mathrm{Hb} \mathrm{D}$. Our results also indicate that $\mathrm{Hb} \mathrm{D}$ has a higher stability than $\mathrm{Hb} \mathrm{A}$ (see

Table 4. Calculated energy of unfolding (kcal/mol) for human and bar-headed goose hemoglobins

\begin{tabular}{llllllllll}
\hline Chains & $E(f)$ & $\Delta G_{\mathrm{h}}(f)$ & $E(u)$ & $\Delta G_{\mathrm{h}}(u)$ & $\Delta E^{\mathrm{t}}$ & $\Delta G_{\mathrm{h}}^{\mathrm{t}}$ & $\Delta G_{u}$ & $E_{v}$ & $E_{e}$ \\
\hline$\alpha \beta(\mathrm{G})$ & -2208 & -274 & -309 & -741 & 1899 & -467 & 1399 & -1435 & -1455 \\
$\alpha(\mathrm{G})$ & -990 & -128 & -123 & -347 & 868 & -219 & & & \\
$\beta(\mathrm{G})$ & -1102 & -156 & -186 & -394 & 916 & -238 & & & \\
$\alpha \beta(\mathrm{H})$ & -2042 & -211 & -235 & -669 & 1807 & -458 & 1349 & -1390 & -1406 \\
$\alpha(\mathrm{H})$ & -732 & -106 & -98 & -318 & 635 & -212 & & & \\
$\beta(\mathrm{H})$ & -816 & -118 & -137 & -350 & 679 & -232 & & & \\
\hline
\end{tabular}

$\alpha \beta, \alpha, \beta$, refer to dimer and monomers, respectively. Human (H), bar-headed goose (G) oxyhemoglobin $E_{v}, E_{e}, f$ and $u$, are van der Waals energy, electrostatic energy, folded and unfolded states, respectively. The energy of unfolding of the bar-headed goose hemoglobin was calculated because of the existence of the three dimensional data in Protein Data Bank and the high homology (\%) relative to graylag goose hemoglobin. 


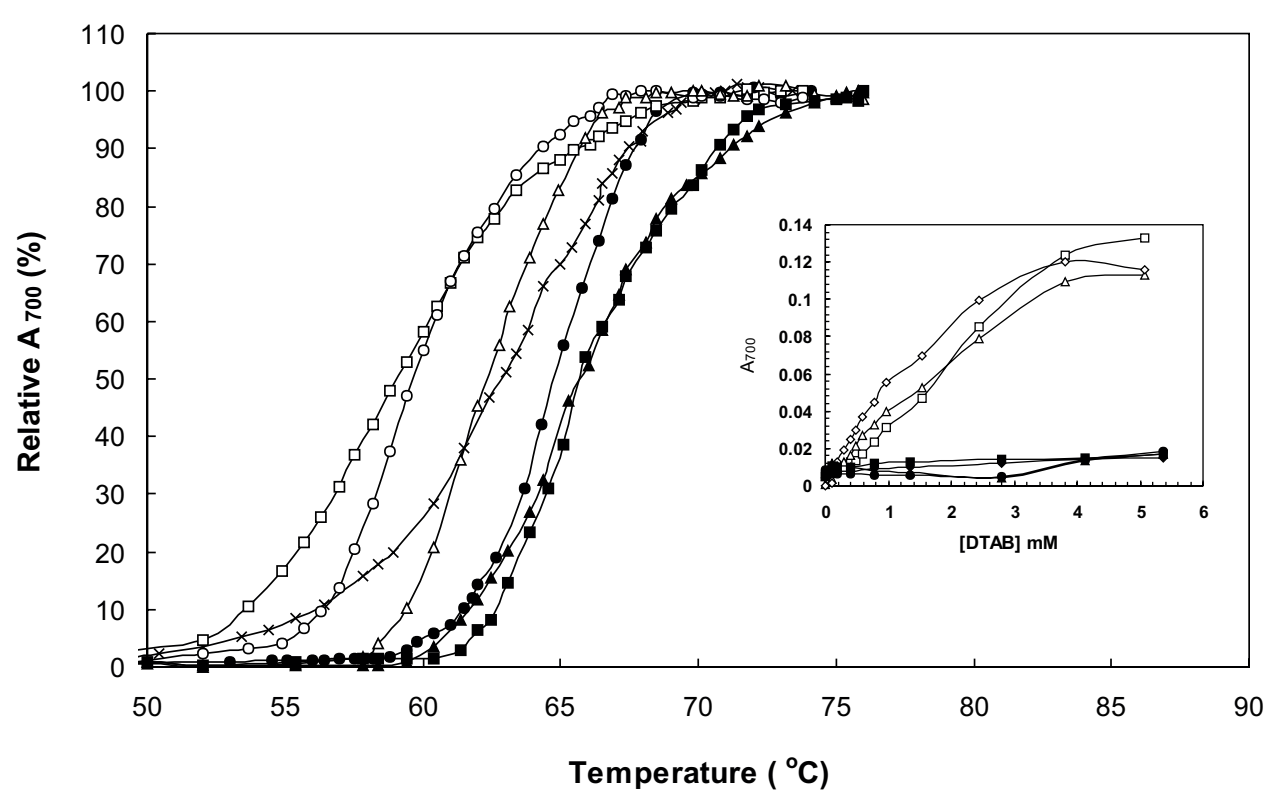

Figure 4. Variation of absorbance at $700 \mathrm{~nm}$ versus temperature for oxyhemoglobin as a measure of turbidity, and versus DTAB concentrations (inset).

The protein concentration for thermal profiles and DTAB curves was $6 \mathrm{mg} / \mathrm{ml}$ and 2 $\mathrm{mg} / \mathrm{ml}$, respectively. Chicken ( $\square$ ), turkey $(O)$, goose $(\Delta)$, human $(\boldsymbol{\Delta})$, bovine (O), horse $(\square)$, sheep ( $\mathbf{x}$ ) hemoglobins.

Table 5). We may conclude that a lower oxygen affinity of hemoglobins corresponds to their higher stability (both in birds and mammals).

Chothia and coworkers (Chothia et al., 1976), reported that the $\mathrm{T}$ state conformation was more stable ( $5 \mathrm{kcal} / \mathrm{mol}$ ) than the $\mathrm{R}$ state
Based on the foregoing facts, we can conclude that the higher hydrophobicity of avian $\mathrm{Hbs}$ is a factor that contributes to higher stability of the $\mathrm{T}$ structure, nearly $20 \mathrm{kcal} / \mathrm{mol}$ (Chothia et al., 1976). Accordingly, the avian $\mathrm{Hb}$ may have a higher $\mathrm{T} / \mathrm{R}$ state ratio than the mammalian $\mathrm{Hb}$.

Table 5. Comparison of surface and stability of some hemoglobins and the effect of inositol hexaphosphate (IHP)

\begin{tabular}{llllll}
\hline & Chicken & \multicolumn{5}{c}{ Human } & Goose \\
\cline { 2 - 6 } & Hb A & Hb D & without IHP & $10 \mathrm{mM} \mathrm{IHP}$ & \\
\hline$T_{\mathrm{m}}$ & 65.2 & 67 & 65 & 68 & - \\
$T(\mathrm{~g})$ & 60.0 & 58.3 & - & - & - \\
$\Delta \mathrm{ASA}^{\mathrm{a}}$ & - & - & 885 & - & 946 \\
$\mathrm{~V}_{\mathrm{G}}{ }^{\mathrm{b}}$ & - & - & 4619 & - & 4134 \\
\hline
\end{tabular}

${ }^{\mathrm{a}} \Delta \mathrm{ASA}$ (in $\AA^{2}$ ) was calculated for $\alpha \beta$ dimer of human and bar-headed goose oxyhemoglobins by the method of Shrake \& Rupley (1973) implemented in Fantom program using (http://www.scsb.utmb.edu) web site; gap volume, $V_{G}$ (in $\AA^{3}$ ) calculated for the dimer of human and bar-headed goose by web site (http://www.biochem.ucl.ac.uk). Temperatures are in ${ }^{\circ} \mathrm{C}$.

long before our findings regarding the presence of forms of the $\mathrm{T}$ state in the avian $\mathrm{Hbs}$ (Chothia et al., 1976). This leads us to believe that the structural conformation of avian $\mathrm{Hbs}$ has a higher content of $\mathrm{T}$ state (deoxy form) in relation to $\mathrm{R}$ state (oxy form).
The gap volume between $\alpha \beta$ subunits was found to be higher in human $\mathrm{Hb}$ than in the bar-headed goose $\mathrm{Hb}$. Table 1 also shows a higher $\mathrm{V}_{\mathrm{t}}$ for the avian $\mathrm{Hb}$. Partial specific volume was also determined from the amino-acids constituents according to Zamyatnin 
(1972). Since the partial specific volume is associated with average hydrophobicity, $\mathrm{H} \phi$, and the compressibility factor is dependent on the partial molal volume $v$, accordingly the empirical formula can be obtained (Gekko \& Hasegawa, 1986) as follows:

$$
v=1.58 \times 10^{-4} \mathrm{H} \phi+0.578
$$

Thus we can conclude not only that a higher $\mathrm{H} \phi$ value corresponds to a higher partial specific volume, but we can also conclude that the partial molal volume of deoxy (T-state) is higher than that of the $\mathrm{R}$ state (Bureau \& Banerjee, 1976). Thus, the higher stability of protein is probably related to a higher partial specific volume. It has been found that the partial specific volume has both a direct and a reverse relationship to the areas of the nonpolar and polar surfaces, respectively (Chalikian et al., 1996). Also our study indicates that the total hydration potential $\left(\mathrm{HP}^{\mathrm{t}}\right)$ has a direct relationship with the polar surfaces, and it has been determined to be higher for the avian $\mathrm{Hb}$. This fact leads to the conclusion that the avian Hbs have a lower tendency to be hydrated (Kharakoze \& Sarvazyan, 1993). The buried surface area of the oligomers is associated with their stabilities. Accordingly, the calculated $\triangle \mathrm{ASA}$ values of alpha-beta dimers for the bar-headed goose $\mathrm{Hb}$ are higher than for the human $\mathrm{Hb}$ (Table 5). The buried surface areas are apparently higher in $\mathrm{T}$ state than they are in $\mathrm{R}$ state (Chothia et al., 1976). Janin \& Chothia (Janin et al., 1988; Janin \& Chothia, 1990) reported twenty three oligomeric proteins with high stabilities which were assumed to be associated with the higher buried surface areas. It has been suggested that the stability of proteins at high temperatures $\left(60-70^{\circ} \mathrm{C}\right)$ is due probably to increasing hydrophobic bondings in the protein (Goldsack, 1970). It is important to note that, in addition to hydrophobic interactions, the electrostatic and van der Waals forces also play substantial roles in the stabilization of protein structures (Chothia et $a l .$, 1976). Table 5 shows the calculated values for each energy contributing source for two $\mathrm{Hb}$ samples (bar-headed goose, human).

Another reason for a higher $\mathrm{T} / \mathrm{R}$ state form for the avian $\mathrm{Hb}$ in relation to mammalian $\mathrm{Hb}$ is a higher turbidity factor and self association of proteins which is believed to be due to a higher hydrophobicity. Figure 4 shows the variation of the absorbance at $700 \mathrm{~nm}$ with temperature and the effect of DTAB as a surfactant factor. We have assumed that these changes are associated with the degree of turbidity. In this case, the protein association seems to be higher for the avian $\mathrm{Hb}$. It is believed that the surfactant either increases the surface hydrophobicity or, may be, neutralizes the surface charges of the hemoglobin of birds, so that this surface hydrophobicity is intrinsically higher in the avian $\mathrm{Hb}$ than it is in mammalian $\mathrm{Hb}$. The literature data indicate that the increment of the surface hydrophobicity raises the association and polymerization of proteins such as $\mathrm{Hb} \mathrm{S}$ (Harrington et al., 1997), and Hb of lamprey (Andersen \& Gibson, 1971). These Hbs become more associated in the deoxy form ( $\mathrm{T}$ state) because the surface hydrophobicity in this state is probably higher than that in the oxy forms. Accordingly, $\mathrm{Hb} \mathrm{D}$ induces a turbidity and polymerization in the avian $\mathrm{Hb}$. The results of differential scanning calorimetry (not shown) at three scan rates $(2,1,0.5$ $\mathrm{K} / \mathrm{min}$ ) based on the method of Cho \& Choy (1980) gave identical results for three $\mathrm{Hb}$ samples. This finding leads us to believe that the kinetics of association of the avian $\mathrm{Hb}$ (including $\mathrm{Hb} \mathrm{D}$ ) is biphasic. This phenomenon has been also observed for Hb S (Reddy et al., 1996; Mu et al., 1998). We have also used $T_{\mathrm{t}}$ to estimate the magnitude of self-association of Hbs. $T_{\mathrm{t}}$ depends on the hydrophobicity of the constituent amino-acid residues (Urry et $a l ., 1992)$ and seems to be lower for the hydrophobic amino acids. Once the value of $T_{\mathrm{t}}$ is above that for the physiological temperature, the polypeptide or protein will be unfolded (disassembled); and once $T_{\mathrm{t}}$ is below 
that for the physiological temperature, the polypeptide or protein will be folded (assembled). The calculated average $T_{\mathrm{t}},\left\langle T_{\mathrm{t}}\right\rangle$, given in Fig. 3 indicates that avian Hbs proteins characterized by higher hydrophobicity have lower $\left\langle T_{\mathrm{t}}\right\rangle$ values. Accordingly, the higher hydrophobicities of avian $\mathrm{Hb}$ have a lower $\left\langle T_{\mathrm{t}}>\right.$.

The authors thank Dr. M. Fooladi for his valuable comments on the manuscript.

\section{R E F E R E N C E S}

Adachi K, Kim J, Travitz R, Harano T, Asakura T. (1987) Effect of amino acid at the $\beta 6$ position on surface hydrophobicity, stability, solubility, and the kinetics of polymerization of hemoglobin. J Biol Chem.; 262: 12920-5.

Adachi K, Kim JY, Konitzer P, Asakura T, Saviola B, Surrey S. (1993) Effects of $\beta 6$ amino acid hydrophobicity on stability of hemoglobin tetramers. FEBS Lett.; 315: 47-50.

Andersen ME, Gibson QH. (1971) A kinetic analysis of the binding of oxygen and carbon monoxide to Lamprey hemoglobin Petromyzon marinus and Petromyzon fluviatilis. J Biol Chem.; 246: 4790-9.

Argos P, Mohana JKR, Hargrave PA. (1982) Structural prediction of membrane-bound proteins. Eur J Biochem.; 128: 565-75.

Bard H, Fouron JC, Groth AM, Soukini MA, Cornet A. (1976) The adaptation of the fetal red cells of newborn lambs to extrauterine life: the role of 2,3-diphosphoglycerate and adult hemoglobin. Pediatr Res.; 10: 823-5.

Bartels H, Hiller G, Reinhardt W. (1966) Oxygen affinity of chicken blood before and after hatching. Respir Physiol.; 1: 345-456.

Bigelow CC, Channon M. (1976) Handbook of Biochemistry and Molecular Biology, Proteins. Fasma GD. ed, vol 1, pp 209-243. CRC Press, Cleveland, $\mathrm{OH}$.

Brygier J, De Bruin SH, Hoof MK, Rollema HS. (1975) The interaction of organic phosphates with human and chicken hemoglobin. Eur $J$ Biochem.; 60: 379-83.

Bull HB, Breese K. (1973) Thermal stability of proteins. Arch Biochem Biophys.; 158: 681-6.

Bureau M, Banerjee R. (1976) Structure - volume relationships in hemoglobin A densitometric and dilatometric study of the oxy deoxy transformation. Biochimie.; 58: 403-7.

Chalikian TV, Totrov M, Abagyan R, Breslauer KJ. (1996) The hydration of globular proteins as derived from volume and compressibility measurement: cross correlating thermodynamics and structural data. J Mol Biol.; 260: 588-603.

Cho KC, Choy CL. (1980) Thermal stability of hemoglobin and myoglobin; effect of spin state. Biochim Biophys Acta.; 622: 320-30.

Chothia S, Wodak S, Janin J. (1976) Role of subunit interfaces in the allosteric mechanism of hemoglobin. Proc Natl Acad Sci U S A.; 73: 3793-7.

Christensen EH, Dill DB. (1965) Oxygen dissociation of bird blood. J Biol Chem.; 109: 443-8.

Clerbaux T, Gustin P, Detry B, Cao ML, Frans A. (1993) Comparative study of the oxyhemoglobin dissociation curve of four mammals: man, dog, horse and cattle. Comp Biochem Physiol.; 106: 687-94.

Cobb JA, Manning D, Kolatkar PR, Cox DJ, Riggs AF. (1992) Deoxygenation-link association of a tetrameric component of chicken hemoglobin. J Biol Chem.; 257: 1183-9.

Coletta M, Ascenzi P, Santucci R, Bertollini A, Amiconi G. (1993) Interaction of inositol hexakisphosphate with liganded ferrous human hemoglobin. Direct evidence for two functionally operative binding sites. Biochim Biophys Acta.; 1162: 309-14.

Gekko K, Hasegawa Y. (1986) Compressibility-structure relationship of globular proteins. Biochemistry.; 25: 6563-71.

Goldsack DE. (1970) Relation between the hydrophobicity index to the thermal stability of homologous proteins. Biopolymers.; 9: 247-52. 
Gustin P, Clerbaux T, Williams E, Lakeux P, Lomba F, Frans A. (1988) Oxygen transport properties of blood in two different bovine breeds. Comp Biochem Physiol A.; 89: 553-8.

Harrington DJ, Adachi K, Royer WE. (1997) The high resolution crystal structure of deoxyhemoglobin S. J Mol Biol.; 272: 398-407.

Irback A, Sanderlin E. (2000) On the hydrophobicity correlation in protein chains. Biophys J.; 79: 2252-8.

Janin J, Miller S, Chothia C. (1988) Surface, subunit interfaces and interior of oligomeric proteins. J Mol Biol.; 204: 155-64.

Janin J, Chothia C. (1990) The structure of protein-protein recognition sites. $J$ Biol Chem.; 265: 16027-30.

Jiang X, Kowalski J, Kelly JW. (2001) Increasing protein stability using a rational approach combining sequence homology and structural alignment: stabilizing the WW domain. Protein Science; 10: 1454-65.

Koehl P, Levitt M. (1999) Structure-based conformational preference of amino acids. Proc Natl Acad Sci U S A.; 96: 12524-9.

Kharakoze DP, Sarvazyan AP. (1993) Hydrational and intrinsic compressibilities of globular proteins. Biopolymers.; 33: 11-26.

Knapp JE, Oliveira MA, Xie Q, Ernst SR, Riggs AF. (1999) The structural and functional analysis of the hemoglobin D component from chicken. J Biol Chem.; 274: 6411-20.

Kumar S, Tsai CJ, Nussinov R. (2000) Factor enhancing protein thermostability. Protein Engineering.; 13: 179-91.

Lenfant C, Kooyman GL, Elsner R, Drabek CM. (1969) Respiratory function of blood of adult and fetus. Am J Physiol.; 216: 1598-600.

Messana I, Angeletti M, Castagnola M, Sanctis GD, Stasio ED, Giardina B, Puciarelli S, Coletta M. (1998) Thermodynamics of inositol hexakisphosphate interaction with human oxyhemoglobin. It is effective in improving oxygen release from tetrameric hemoglobins. J Biol Chem.; 273: 15329-34.
Moss BA, Hamilton EA. (1974) Chicken definitive erythrocyte hemoglobin. Biochim Biophys Acta.; 371: 379-91.

Mu X, Makowski L, Magdoff-Fairchild B. (1998) Analysis of stability of hemoglobin S double strands. Biophys J.; 74: 655-68.

Naderi-manesh H, Sadeghi M, Arab S, Moosavi-Movahedi AA. (2001) Prediction of protein surface accessibility states using information theory. Proteins: Structure, Function, Genetics.; 42: 452-9.

Ooi T, Oobatake M, Nemety G, Scheraga H. (1987) Accessible surface areas as a measure of thermodynamic parameters of hydration of peptides. Proc Natl Acad Sci U S A.; 84: 3086-90.

Perutz MF. (1983) Species adaption in a protein molecule. Mol Biol Evol.; 1: 1-28.

Petruzzelli R, Aureli G, Lania A, Galtieri A, Desideri A, Giardina B. (1996) Diving behavior and haemoglobin function: the primary structure of the $\alpha$-and $\beta$-chains of the sea turtle (Caretta caretta) and its functional implications. Biochem J.; 316: 959-65.

Prakash V, Timasheff SN. (1985) Calculation of partial specific volumes of proteins in $8 \mathrm{M}$ urea solution. Methods Enzymol.; 117: 53-60.

Reddy LR, Reddy KS, Surrey S, Adachi K. (1996) Role of hydrophobic amino acids at beta and beta 88 in stabilizing $\mathrm{F}$ helix conformation of hemoglobin S. J Biol Chem.; 271: 24564-8.

Rollema H, Bauer C. (1979) The interaction of inositol pentaphosphate with the hemoglobins of highland and lowland geese. J Biol Chem.; 254: 12038-43.

Shrake A, Rupley JA. (1973) Environment and exposure to solvent of protein atoms, lysozyme and insulin. J Mol Biol.; 79: 351-71.

Tuker VA. (1972) Metabolism during flight in the laughing gulls, Larus articilla. Am J Physiol.; 222: 237-45.

Urry DW, Gowda DC, Parker TM, Luan C, Reid MC, Harris CM, Pattanaik A, Harris RD. (1992) Hydrophobicity scale for proteins 
based on inverse temperature transitions. Biopolymers.; 22: 1243-50.

Wagschal K, Tripet B, Hodges RS. (1999) De novo design of a model peptide sequence to examine the effects of single amino acid substitutions in the hydrophobic core on both stability and oligomerization state of coiled-coils. J Mol Biol.; 285: 785-803.

Williams RC, Tsay KY. (1973) A convenient chromatographic method for the preparation of human hemoglobin. Anal Biochem.; 54: 137-45.

Yang T, Olsen KW. (1988) Effect of crosslinking on the thermal stability of hemoglobins II. The stabilization of met-, cyanomet-, and carbonmonoxyhemoglobins A and $\mathrm{S}$ with bis(3,5-dibromosalycil) fumarate. Arch Biochem Biophys.; 261: 283-90.

Yohe ME, Sheffield KM, Mukerji I. (2000) Solubility of fluromethemoglobin S, effect of phosphate and temperature on polymerization. Biophys J.; 78: 3218-26.

Zamyatnin AA. (1972) Protein volume in solution. Prog Biophys Mol Biol.; 24: 107-23.

Zhang J, Hua Z, Tame JRH, Lu G, Zhang R, Gu X. (1996) The crystal structure of a high oxygen affinity species of hemoglobin (Bar-headed goose hemoglobin in the oxy form). $J \mathrm{Mol}$ Biol.; 255: 484-93. 